Plant Tissue Cult. \& Biotech. 21(2): 169-180, 2011 (December)

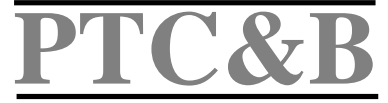

\title{
Lentil Regeneration from Cotyledon Explant Bearing a Small Part of the Embryo Axis
}

\author{
F. Zaker Tavallaie, B. Ghareyazie ${ }^{1}$, A. Bagheri ${ }^{2}$ and K.K. Sharma ${ }^{3}$ \\ Department of Plant Production Technology, Shirvan Faculty of Agriculture, Ferdowsi \\ University of Mashhad; Mashhad, Iran \\ Key words: Regeneration, Cotyledon, Embryo axis, Lentil, Lens culinaris
}

\begin{abstract}
The effect of external BAP on explants including leaflets, stems, cotyledons with and without embryo axis of lentil (Lens culinaris Medic.) were tested on the frequency of shoot induction. The effect of different levels and combinations of various cytokinins on multiple shoot induction and elongation of shoots were compared. The effect of explant age and $\mathrm{pH}$ of media were also tested on shoot induction from various explants. Finally, the effect of IBA, IAA, and NAA on root induction of elongated shoots were examined. Optimum conditions for root emergence and growth and the hardening of seedlings were determined. Cotyledon with small part of the embryo axis was the superior explant. Shoot induction from the explants was enhanced by inclusion of BAP in the seed germination medium. The highest shoot induction (up to 96\%) was obtained on MS with $7.5 \mu \mathrm{M}$ 2-ip, $4 \mu \mathrm{M} \mathrm{Kn}$, and $2 \mu \mathrm{M}$ TDZ. Over $80 \%$ of the elongated shoots produced roots in solid $1 / 4$ BS media with $50 \mu \mathrm{M}$ NAA for 3 days followed by 10 days in a mixture of liquid $1 / 4$ BS, Vermiculite and sand. Root development and hardening of the seedlings was achieved by using a hydroponics system containing Arnon's solution. Tissue culture derived plants were transplanted to the greenhouse where the seeds were harvested after about 4 months.
\end{abstract}

\section{Introduction}

Regeneration and growth of shoots from various seedling-derived explants have been found to be recalcitrant in the legumes (Sharma et al. 2005). Lentil (Lens culinaris Medic. cv. Gachsaran) was regenerated by organogenesis from shoot apices (Bajaj and Dhanju 1979, Williams and McHughen 1986), somatic embryogenesis from embryo-derived callus cultures (Saxena and King 1987; Polanco et al. 1988), nodal explants (Polanco et al. 1988, Singh and Raghuvanshi

\footnotetext{
${ }^{1}$ Agricultural Biotechnology Research Institute of Iran (ABRII), Karaj, Iran. ${ }^{2}$ Department of Plant Biotechnology, Faculty of Agriculture, Ferdowsi University of Mashhad, Mashhad. ${ }^{3}$ International Crops Research Institute for the Semi-Arid Tropics (ICRISAT), Patancheru 502324, Andhra Pradesh, India.
} 
1989), intact seedlings (Malik and Saxena 1992), immature seeds (Polanko and Ruiz 2001), cotyledonary nodes (Gulati et al. 2001, Talib et al. 2003), and decapitated embryos (Sarker et al. 2003, Ghasemi et al. 2008).

There are only a few reports of rooting from in vitro regenerated shoots in lentil where the frequency of rooting has been very low. Gulati et al. (2001) obtained root only by micro-grafting the shoots that were regenerated from the cotyledonary node explants. In vitro rooting was examined for lentil nodal segments to study the effect of orientation on rooting. Some enhancement of root induction has been observed from segments with reverse orientation (Fratini and Ruiz 2003). However, Newell et al. (2006) suggested that the medium aeration at the proximal end of the micro-cutting is more important than shoot orientation for in vitro rooting of lentil micro-cuttings. Reports on rooting of tissue culture derived lentil plantlets indicate that cotyledonary nodes (Gulati et al. 2001), nodal segments (Fratini and Ruiz 2003) and intact seeds (Newell et al. 2006) are most suitable as explants. However, Ye et al. (2002) and Sarker et al. (2003) suggested that these explants are not ideal for Agrobacterium-based genetic transformation of lentil, since it is difficult for the Agrobacterium to access the meristemic parts during the co-cultivation process. The choice of a proper explant for the efficient genetic transformation followed by successful regeneration of whole transgenic plants of lentil, is therefore very valuable. In this research, we have developed an efficient protocol for the regeneration of lentil plants from the cotyledon explants derived from in vitro raised seedlings where a small part of embryo axis is retained.

\section{Materials and Methods}

Mature seeds of lentil (Lens culinaris Medic.), cv. Gachsaran (ILL6212) were surface sterilized by washing with $70 \%$ (v/v) ethanol for $1 \mathrm{~min}$, followed by $0.1 \%$ mercuric chloride mixed with two drops of Tween 20 for 7 min and rinsed $5-7$ times in sterile distilled water. The seeds were then soaked for $2 \mathrm{hrs}$ in sterile water prior to removing their seed coat and kept for germination on MS medium (Murashige and Skoog 1962) solidified with 1.0\% Difco Bacto agar and containing $4 \mu \mathrm{M}$ BA for 7 - 10 days.

The following four types of explants were excised from the germinated seedlings: leaflet (L), stem (S), cotyledon without embryo axis (C), and cotyledon with a small part of embryo axis (CEA). These explants were cultured on a shoot induction media (MS with $10 \mu \mathrm{M}$ 2-ip). The explants were counted and the data were recorded after eight days. A completely random design model with 8 replicates was used for statistical analysis. Each replicate included 20 explants in one petri dish. 
The effect of application of external BAP during seed germination was also tested on the shoot induction of CEA explants. CEA explants were prepared from 15-day-old seedlings. 100 seeds were cultured on each of the MS with or without $4 \mu \mathrm{M}$ BAP. After 7 days, explants were sub-cultured onto a shoot induction medium (10 $\mu \mathrm{M}$ 2-ip). After eight days, explants with multiple shoots were counted and the percentage of shoot induction was calculated. Explants with multiple shoots were counted after eight days and analyzed with student's t-test.

The effects of various levels and combinations of 2-ip, Kn and TDZ were tested on multiple shoot induction using CEA explants in three experiments. In the first experiment, the effects of various concentrations of 2-ip $(2-20 \mu \mathrm{M})$, and, in the second experiment, the effect of a constant amount of 2-ip $(7.5 \mu \mathrm{M})$ in combination with 2, 4 and $10 \mu \mathrm{M} \mathrm{Kn}$, TDZ, and $\mathrm{Kn}+\mathrm{TDZ}$ were compared separately (Table 1). Using the best level of Kn and TDZ obtained in the second experiment, the effects of various level of 2-ip were compared on shoot induction in the third experiment (Table 2). Each treatment containing different combinations of hormones was named as S1 to S21 ( $\mathrm{S}=$ Shoot induction media) as shown in Tables 1 and 2. Fifty explants were placed on each medium. The number of explants containing shoots and the number of shoots per explant were recorded. CRD was used and means were compared using DMRT at a 0.01 probability level.

The explants containing multiple shoot buds were then transferred to the MS medium containing various combinations and concentrations of plant growth regulators (PGRs) in order to determine the best media for shoot elongation. Each treatment, containing specific compositions of hormones, was named SEM1 to SEM10 (SEM = Shoot elongation media) (Table 3). Clusters of shoots were separated and sub-cultured into fresh medium every six days until they were ready to be used for root induction. The number of elongated shoots with lengths equal to or longer than $3 \mathrm{~cm}$ were counted for each explant. CRD was used as experimental design and data were analyzed. Means were compared using DMRT at 0.01 probability level.

Five different methods of root induction were used as shown in Table 1. In fifth method, the shoots were subsequently transferred into an autoclaved mixture of Vermiculite, sand and $1 / 4$ strength liquid BS for 10 days for the emergence and growth of induced roots. The number of rooted shoots were counted and the percentage of root induction was determined.

Rooted shoots were transferred to the hydroponic system containing halfstrength Arnon's solution (Arnon 1938) for root proliferation for seven days. The average number of roots per shoot and their length were measured for each 
treatment. The roots of the plantlets were dipped in a diluted fungicide Carboxin-Tiram solution and were then transferred to $20 \mathrm{~cm}$ diameter pots containing red soil. These plants were covered partially with transparent polythene bags to facilitate hardening of the transplanted plantlets. After three days the corners of the covers were cut for controlling the humidity and after seven days the covers were removed. The photoperiod regime was maintained at $16 / 8 \mathrm{hrs}$ light/dark with $25^{\circ} \mathrm{C}$ during the day and $15^{\circ} \mathrm{C}$ at night. The pots were irrigated every two days for two weeks followed by irrigation every 4 - 5 days for three months. The Arnon's solution was used at an interval of once per week as supplementation in the glasshouse. After 3 - 4 months seeds were harvested from the in vitro-regenerated plants.

Table 1. Different methods followed for root induction from in vitro regenerated shoots of lentil.

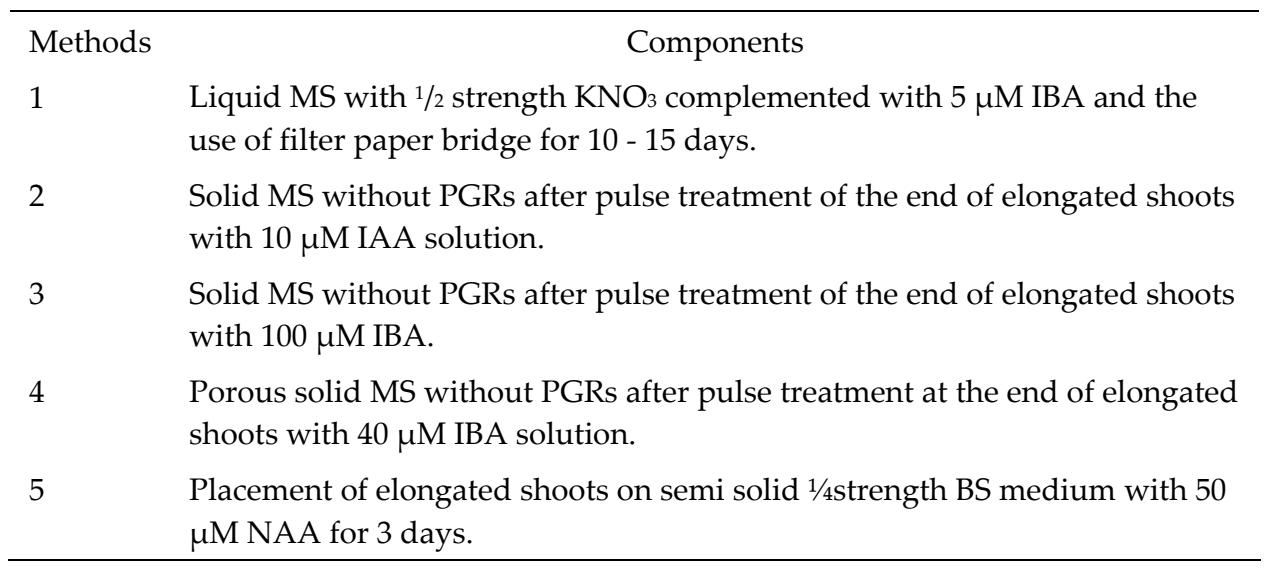

\section{Results and Discussion}

Cotyledon explants with a small part of embryo axis (CEA) was found to produce the highest number of shoots when compared to other explants (Fig. 3A) from which up to $78.5 \%$ of multiple shoots were obtained. Application of various plant growth hormones improved the percentage of shoot induction (96\%), with some individual explants producing up to a maximum of 40 shoots.

The inclusion of BAP in the seed germination media for the explant donor seedlings enhanced multiple shoots in the respective explants (Fig. 2). However, the external application of BAP in explants resulted in a high percentage of shoot induction. Regarding the enhancement of shoot induction in explants derived from seedlings on MS medium containing BAP, it appears that the germination and growth of seedlings resulted in reduced root production and enhanced shoot 
production. Hence, the seedlings were ready to be used for preparation of explants faster in comparison with no BAP treatment.

There was no significant difference in shoot induction percentage among explants derived from seedlings of 7 to 13 days old but comparatively seven day old explants were found to produce more number of shoots in the next stages.

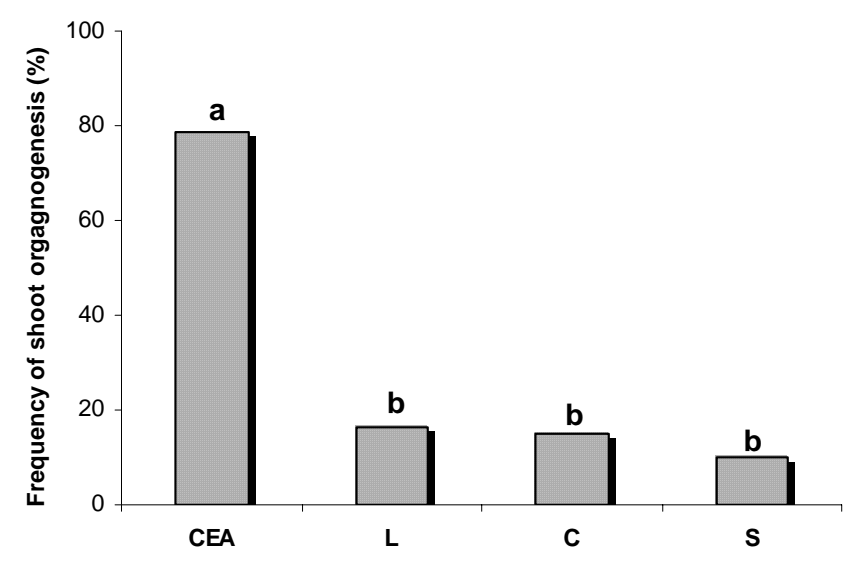

Fig. 1. Percentage of multiple shoot induction of four explants on MS with $10 \mu \mathrm{M}$ 2-ip. (CEA = Cotyledon with a small part of embryo axis, $\mathrm{L}=$ Leaflet, $\mathrm{C}=$ Cotyledon without embryo axis, $\mathrm{S}=$ Stem).

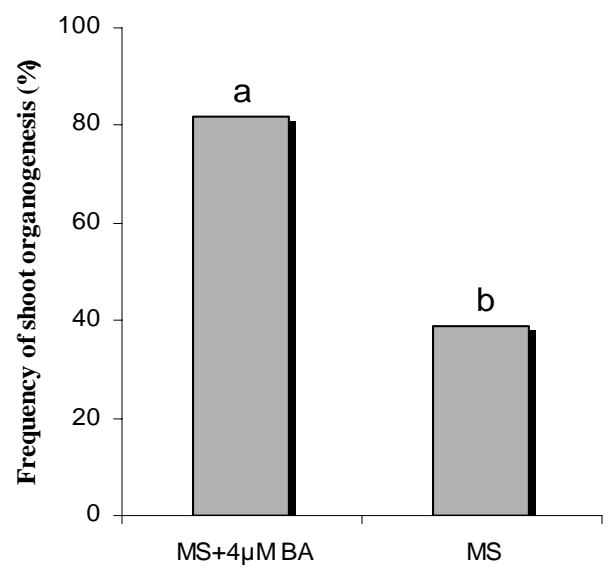

Fig. 2. Effects of inclusion of external BA during seed germination media on shoot induction in lentil.

Primary experiments (data not shown) using a wide range of 2-ip revealed the superiority of $5-15 \mu \mathrm{M}$ of 2-ip, which resulted in higher number of shoot induction in comparison with other concentrations tested. The combination of 2ip, Kn and TDZ induced more shoots than 2-ip alone (Table 1). Similarly, more number of shoots were obtained from the application of $4 \mu \mathrm{M} \mathrm{Kn}$ in comparison with 2 and $10 \mu \mathrm{M}$ (Table 2). 
Similarly, shoot induction increased with the increase of TDZ concentrations and the combination of 2-ip, Kn and TDZ resulted in more number of shoots in comparison with the combination of 2-ip with Kn or 2-ip with TDZ. Treatments of S11 and S12 (Table 2) produced the highest number of multiple shoots among the tested treatments $(\mathrm{p}<0.01)$. However, considering the disadvantages of the application of higher concentrations of TDZ on the next stages, treatment S11 (MS with $7.5 \mu \mathrm{M}$ 2-ip, $4 \mu \mathrm{M}$ Kn and $2 \mu \mathrm{M}$ TDZ) was selected. Results obtained from the experiment with various concentrations of 2-ip in combination with 4 $\mu \mathrm{M} \mathrm{Kn}$ and $2 \mu \mathrm{M}$ TDZ (Table 3) showed that increasing the concentration of 2-ip from 5 to $7.5 \mu \mathrm{M}$, in combination with $\mathrm{Kn}$ and TDZ, improved shoot induction. Finally, treatment S18 induced more shoots in the explant CEA. So, MS with 7.5 $\mu \mathrm{M}$ 2-ip, $4 \mu \mathrm{M} \mathrm{Kn}$ and $2 \mu \mathrm{M}$ TDZ was selected as the best composition for shoot induction. Using this combination, up to $96 \%$ multiple shoot induction and 40 shoots per explant were obtained.

Table 2. Effect of various combinations and concentrations of $\mathrm{Kn}$ and TDZ in combination with $7.5 \mu \mathrm{M}$ 2-ip on multiple shoot induction using explants of CEA of lentil.

\begin{tabular}{lcclc}
\hline Media & $\begin{array}{c}\text { Kn } \\
(\mu \mathrm{M})\end{array}$ & $\begin{array}{c}\text { TDZ } \\
(\mu \mathrm{M})\end{array}$ & $\begin{array}{l}\text { Mean of shoots } \\
\text { per explant }\end{array}$ & $\begin{array}{c}\text { Frequency of shoot } \\
\text { organogenesis }(\%)\end{array}$ \\
\hline S1 & - & - & $18.4 \pm 1.1 \mathrm{ef}$ & 60.0 \\
S2 & 2 & - & $20.8 \pm 0.9 \mathrm{~d}$ & 62.0 \\
S3 & 4 & - & $21.0 \pm 0.4 \mathrm{dg}$ & 66.0 \\
S4 & 10 & - & $16.0 \pm 0.6 \mathrm{~h}$ & 58.0 \\
S5 & - & 2 & $14.8 \pm 0.9 \mathrm{hi}$ & 42.0 \\
S6 & - & 4 & $15.2 \pm 0.9 \mathrm{hi}$ & 50.0 \\
S7 & - & 10 & $23.0 \pm 0.6 \mathrm{hi}$ & 46.0 \\
S8 & 2 & 2 & $18.8 \pm 0.6 \mathrm{ef}$ & 70.0 \\
S9 & 2 & 4 & $25.6 \pm 0.5 \mathrm{cde}$ & 66.0 \\
S10 & 2 & 10 & $18.0 \pm 0.5 \mathrm{e} \mathrm{f}$ & 76.0 \\
S11 & 4 & 2 & $30.0 \pm 0.0 \mathrm{a}$ & 88.0 \\
S12 & 4 & 4 & $28.8 \pm 0.6 \mathrm{a}$ & 74.0 \\
S13 & 4 & 10 & $23.8 \pm 1.2 \mathrm{cb}$ & 56.0 \\
S14 & 10 & 2 & $23.0 \pm 0.8 \mathrm{c}$ & 62.0 \\
S15 & 10 & 4 & $20.0 \pm 0.7 \mathrm{ef}$ & 68.0 \\
S16 & 10 & 10 & $17.8 \pm 0.9 \mathrm{fg}$ & 62.0 \\
\hline
\end{tabular}

${ }^{*}$ Means that are similar for at least one character are not significantly different, based on DMRT $(\mathrm{p}<0.01)$.

The interval of sub-cultures was also important in determining the effect of various concentrations of PGRs. With 4 days intervals more shoots were obtained in comparison with 8 or more days interval $(\mathrm{p}<0.01)$. In previous studies, $\mathrm{Kn}$ (Sarker et al. 2003, Talib et al. 2003), TDZ (Malik and Saxena 1992, Khawar et al. 
2004), BA (Sarker et al. 2003, Ghasemi et al. 2008), BA (Polanco et al. 1988, Malik and Rashid 1989, Warkentin and McHughen 1993, Talib et al. 2003), and BA+NAA (Saxena and King 1987, Polanco et al. 1988) have been used for shoot induction. While Jayanand et al. (2003) used 2-ip for shoot induction in chickpea plants, this is the first report on the use of 2-ip for shoot induction in lentil.

As shown in Table 4, significant differences were observed on shoot elongation in response to different treatments of the application of Kn and 2-ip. The elongation of shoots in MS with $4 \mu \mathrm{M}$ 2-ip and $1 \mu \mathrm{M}$ Kn was higher than that of other treatments.

Table 3. Effect of various concentrations of 2-ip in combination with $4 \mu \mathrm{M} \mathrm{Kn}$ and $2 \mu \mathrm{M}$ TDZ on multiple shoot induction using explants of CEA in lentil.

\begin{tabular}{lllc}
\hline Media & $\begin{array}{c}\text { 2-ip } \\
(\mu \mathrm{M})\end{array}$ & $\begin{array}{c}\text { Mean of } \\
\text { shoots/explant }\end{array}$ & $\begin{array}{c}\text { Frequency of shoot } \\
\text { organogenesis }(\%)\end{array}$ \\
\hline S17 & 5 & $20.0 \pm 0.8 \mathrm{ed}^{*}$ & 96.0 \\
S18 & 7.5 & $27.4 \pm 0.9 \mathrm{a}$ & 96.0 \\
S19 & 10 & $25.1 \pm 0.7 \mathrm{~b}$ & 88.0 \\
S20 & 12.5 & $16.0 \pm 0.7 \mathrm{hg}$ & 80.0 \\
S21 & 15 & $13.6 \pm 0.9 \mathrm{ji}$ & 76.0 \\
\hline
\end{tabular}

*Means that are similar for at least one character are not significantly different, based on DMRT $(\mathrm{p}<0.01)$.

Table 4. Effect of various concentrations of PGRs (all in $\mu \mathrm{M}$ ) on shoot elongation in lentil.

\begin{tabular}{lcccccc}
\hline $\begin{array}{l}\text { Shoot elongation } \\
\text { media }\end{array}$ & 2-ip & Kn & TDZ & GA3 & BA & $\begin{array}{c}\text { Av. No. of shoots longer } \\
\text { than } 3 \mathrm{~cm} \text { per explant }\end{array}$ \\
\hline SEM1 & 5 & 1 & 2 & - & - & $1.5 \mathrm{~g}^{*}$ \\
SEM2 & 5 & 2 & - & - & - & $8 \mathrm{c}$ \\
SEM3 & 5 & - & - & - & - & $8.5 \mathrm{c}$ \\
SEM4 & 2 & 1 & - & - & - & $10 \mathrm{~b}$ \\
SEM5 & 4 & 1 & - & - & - & $15 \mathrm{a}$ \\
SEM6 & - & - & - & - & 1 & $5 \mathrm{f}$ \\
SEM7 & - & - & - & - & 2.5 & $6.5 \mathrm{ef}$ \\
SEM8 & - & - & - & - & 5 & $6.5 \mathrm{de}$ \\
SEM9 & - & - & - & 2 & - & $7.5 \mathrm{~cd}$ \\
SEM10 & - & - & - & - & - & $5.5 \mathrm{ef}$ \\
\hline
\end{tabular}

* Means that are similar for at least one character are not significantly different, based on DMRT $(\mathrm{p}<0.01)$.

Comparisons between method 2 and methods 1, 3 and 4 indicated that the application of IBA was more effective than IAA in increasing the number of 
roots in lentil. A filter paper bridge using liquid MS with $5 \mu \mathrm{M}$ IBA resulted in $20 \%$ rooting only. In the fourth method consisting of porous solid MS after pulse treatment with IBA solution, the percentage of rooting was still low $(29 \%)$. Based on the results shown in Table 5, method 5 produced a higher number of roots in comparison with the other methods tested. The application of 1 and $2 \%$ sucrose in root induction media had no affect on the frequency of rooting. We used sucrose only for 3 days in the root induction media and it was not used in the media used in next steps. The hydroponic system using half Arnon solution (Arnon 1938) improved the development of roots and hardening of seedlings. Immersing roots in fungicide solution to avoid contamination was necessary before transferring to the glasshouse. After 3.5 - 4 months, seeds from matured plants were harvested successfully.

Table 5. Comparison between different methods for root induction from shoots in lentil.

\begin{tabular}{|c|c|c|c|}
\hline Methods & $\begin{array}{l}\text { No. of } \\
\text { cultured } \\
\text { shoots }\end{array}$ & $\begin{array}{c}\text { No. of } \\
\text { shoots } \\
\text { with root }\end{array}$ & $\begin{array}{l}\text { Frequency of } \\
\text { rooting (\%) }\end{array}$ \\
\hline $\begin{array}{l}\text { Medium } 1 \text { containing liquid MS with } 1 / 2 \\
\mathrm{KNO}_{3} \text { with } 5 \mu \mathrm{M} \text { IBA using filter paper } \\
\text { bridge for } 10 \text { - } 15 \text { days. }\end{array}$ & 50 & 10 & 20 \\
\hline $\begin{array}{l}\text { Medium } 2 \text { containing solid MS without } \\
\text { PGRs after pulse treatment of the end of } \\
\text { elongated shoots in } 10 \mu \mathrm{M} \text { IAA solution. }\end{array}$ & 54 & 6 & 11 \\
\hline $\begin{array}{l}\text { Medium } 3 \text { containing solid MS without } \\
\text { PGRs after pulse treatment of the end of } \\
\text { elongated shoots in } 100 \mu \mathrm{M} \text { IBA. }\end{array}$ & 50 & 7 & 14 \\
\hline $\begin{array}{l}\text { Medium } 4 \text { containing porous solid MS } \\
\text { without PGRs after pulse treatment of the } \\
\text { end of elongated shoots into } 40 \mu \mathrm{M} \text { IBA } \\
\text { solution. }\end{array}$ & 45 & 13 & 29 \\
\hline $\begin{array}{l}\text { Method } 5 \text { including placement of } \\
\text { elongated shoots on semi solid } 1 / 4 \text { BS } \\
\text { medium with } 50 \mu \mathrm{M} \text { NAA for } 3 \text { days to } \\
\text { induce roots followed by } 10-15 \text { days } \\
\text { incubation in autoclaved mixture of } \\
\text { vermiculite, sand and } 1 / 4 \text { strength liquid BS } \\
\text { for emergence and growth of induced } \\
\text { roots. }\end{array}$ & 52 & 42 & 81 \\
\hline
\end{tabular}

Based on the results, the application of IBA was more effective for rooting than IAA in increasing the number of roots in lentil. In previous studies, MS with IBA (25 mg/l) had 25\% rooting (Khawar and Özcan 2002; Sarker et al. 2003). A 
filter paper bridge using liquid MS with $5 \mu \mathrm{M}$ IBA resulted in $90 \%$ root induction in chickpea plants (Jayanand et al. 2003); but using this method in lentil, in our study, resulted in $20 \%$ rooting only. We followed the reports of Jayanand et al. (2003) and Newel et al. (2006) on the effect of aeration on root induction for designing the fourth method. The positive effects of aeration was documented in our study using this method but the percentage of rooting was low (29). One justification for this result might be the osmotic stress resulting from low humidity that caused a reduction in root induction frequency.
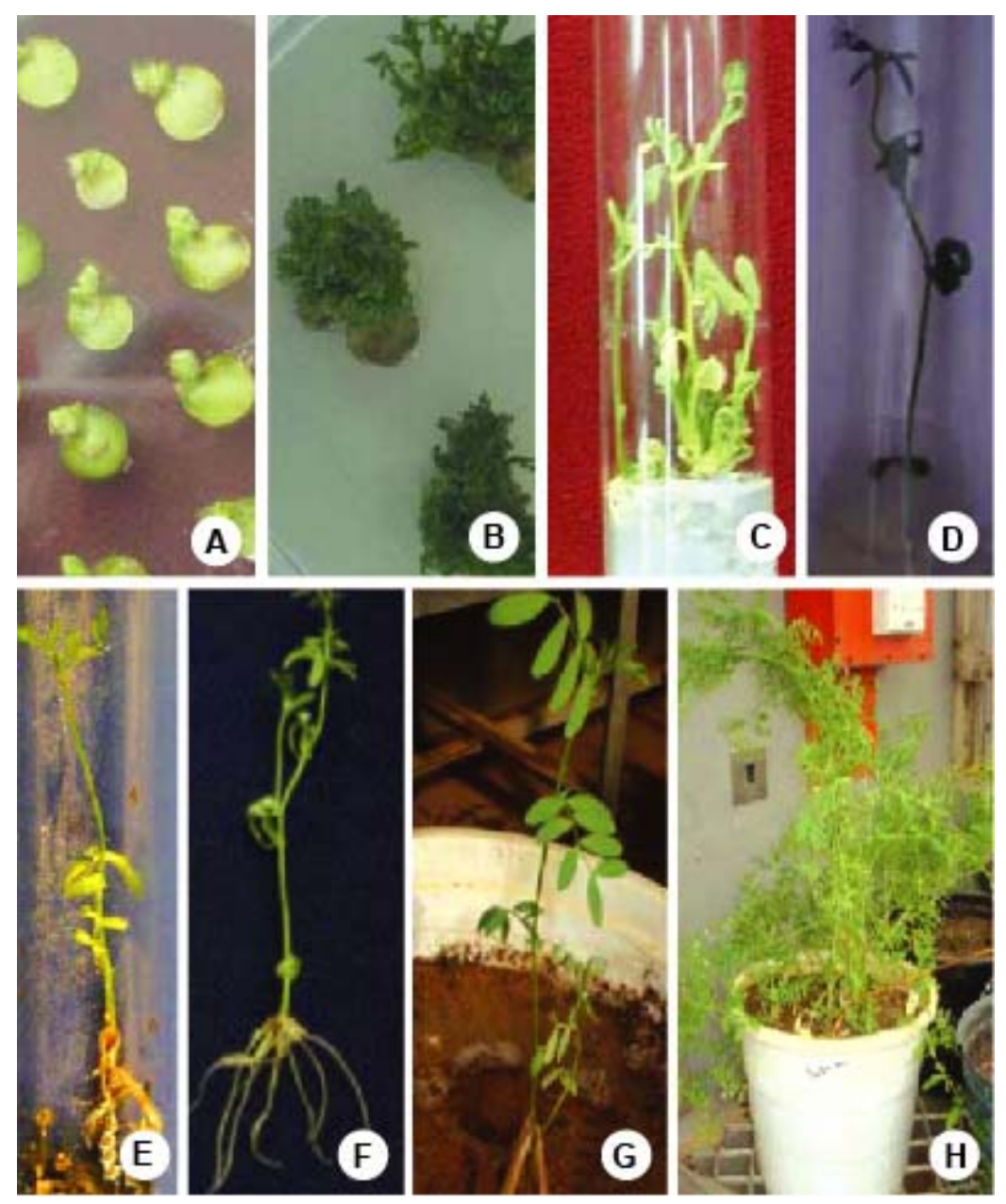

Fig. 3. (A) CEA explants derived from in vitro germinated seedlings of lentil. (B) Explants with multiple shoots after 15 days in MS with $7.5 \mu \mathrm{M}$ 2-ip, $4 \mu \mathrm{M} \mathrm{Kn}$ and $2 \mu \mathrm{M}$ TDZ. (C) Elongation of shoots in MS with $4 \mu \mathrm{M}$ 2-ip and $1 \mu \mathrm{M}$ Kn. (D) Elongated shoots in BS with 50 $\mu \mathrm{M}$ NAA for 3 days to induce root. (E) Appearance and growing of induced roots in a mixture of liquid 1/4 BS (without sucrose), sand and Vermiculite. (F) A seedling with developed roots after 7 days in hydroponic system. (G) Transferring of seedling to glasshouse. (H) A mature plant with seeds in glasshouse. 
Osmotic stress may have resulted from using higher concentrations of agar for solidification of media than was needed to produce porous media. Reports on the use of NAA for root induction are numerous. Different concentrations of NAA including $0.2 \mathrm{mg} / \mathrm{l}$ (Polanco and Ruiz 2001), $1.5 \mathrm{mg} / \mathrm{lit}$ (Ye et al. 2002), and $10 \mathrm{mg} / \mathrm{l}$ (Ghasemi et al. 2008) were used in the semi-solid MS; $1 \mathrm{mg} / \mathrm{l}$ was used in the hydroponic system (Talib et al. 2003) and $1 \mathrm{mg} / \mathrm{l}$ was used in combination with Kn (Fratini and Ruiz 2003). Despite previous studies on root induction in lentil, these studies did not result $\mathrm{n}$ significant root induction and there is no report of successful rooting in lentil. Hence, the finding of high root induction in this study is valuable in lentil regeneration.

It has been reported that the type of explant and combinations of shoot induction media are effective for root induction (Sarker et al. 2003). Immature seeds (Polanco and Ruiz 2001), intact seeds (Ye et al. 2002), decapitated embryos (Sarker et al. 2003 and Ghasemi et al. 2008) and cotyledonary nodes (Talib et al. 2003) were already used as explants. Frantini and Ruiz (2003) used pieces of stem to induce root. A concentration of more than $50 \mu \mathrm{M}$ NAA and a duration of more than 3 days caused necrosis of shoots and sometimes death of the plant. Induction of roots, using selected methods, was carried out in solid media. But aeration was needed for the emergence and growth of induced roots.

In this investigation, several conditions of tissue culture were optimized for culture and regeneration of lentil. These include type and age of explants, combinations and concentrations of PGRs for multiple shoot induction, elongation of induced shoots, root induction on tissue culture derived shoots, root development, and hardening and transplantation of the regenerated plantlets. Our preliminary studies on genetic transformation of lentil using the CEA indicated that this explant can be used as an appropriate material for gene transfer using both Agrobacterium and biolistic methods (data not shown). and using this protocol, higher frequencies of transformation and regeneration of whole transgenic plants in lentil can be achieved.

\section{Acknowledgments}

Authors thank the Genetic Transformation Laboratory team of ICRISAT for their technical help and the use of their facilities, and to the Iran National Science Foundation for financial support.

\section{References}

Arnon DI (1938) Microelements in culture solution experiment with higher plants. Amer. J. Bot. 25: 322-325. 
Bajaj YPS and Dhanju MS (1979) Regeneration of plants from apical meristem tips of some legumes. Curr. Sci. 84: 906-907.

Fratini R and Ruiz ML (2003) A rooting procedure for lentil (Lens culinaris Medik) and other hypogenous legumes (pea, chickpea and Lathyurus) based on explant polarity. Plant Cell Rep. 21: 726-732.

Ghasemi OV; Bagheri A and Moshtaghi N (2008) Direct in vitro regeneration of lentil (Lens culinaris Medik). Pakistan J. Science 11: 2237-2242.

Gulati A; Schryer P and McHughen A (2001) Regeneration and micrografting of lentil shoots. In Vitro Cell. Dev. Biol.- Plant 37: 798-802.

Jayanand B, Sudarsanam G and Sharma KK (2003) An efficient protocol for the regeneration of whole plants of chickpea (Cicer arietinum L.) by using axillary meristem explants derived from in vitro germinated seedlings. In Vitro Cell. Dev. Biol.-Plant 39: 171-179.

Khawar KM, Sancak C, Uranbey S and Özcan S (2004) Effect of thidiazuron on shoot regeneration from different explants of lentil (Lens culinaris M.) via organogenesis. Turk. J. Bot. 28: 421-426.

Khawar KM and Özcan S (2002) Effect of indole-3-Butyric Acid on in vitro root development in lentil (Lens culinaris M.). Turk. J. Bot. 26: 109-111.

Malik KA and Saxena PK (1992) Thidiazuron induces high-frequency shoot regeneration in intact seedlings of pea (Pisum sativum); chickpea (Cicer arietinum) and lentil (Lens culinaris). Australian J. Plant Physiol. 19: 731-740.

Malik MA and Rashid A (1989) Induction of multiple-shoots from cotyledonary node of grain legumes: pea and lentil. Biol. Plant. 31: 230-232.

Murashige T and Skoog F (1962) A revised medium for rapid growth and bioassays with tobacco tissue culture. Physiol. Plant 15: 473-497.

Newell C, Growns D and Mccomb J (2006) Aeration is more important than shoot orientation when rooting lentil (Lens culinaris M. ) cv. "digger" microcuttings in vitro. In Vitro Cell. Dev. Biol.-Plant 42: 197-200.

Polanco M C, Pelaez M I and Ruiz M L (1988) Factors affecting callus and shoot formation in in vitro cultures of Lens culinaris Medik. Plant Cell Tissue Organ Cult. 15:175-182.

Polanco MC and Ruiz ML (2001) Factors that affect plant regeneration from in vitro culture of immature seeds in four lentil cultivars. Plant Cell Tissue Organ Cult. 66: 133-139.

Sarker RH, Mustafa BM, Biswas A; Mahbub S, Nahar M, Hashem R and Hoque MI (2003) In vitro regeneration in lentil (Lens culinaris M.). Plant Tissue Cult. 13: 155-163.

Saxena PK and King J (1987) Morphogenesis in lentil plant regeneration from callus cultures of Lens culinaris M. via somatic embryogenesis. Plant Sci.. 52: 223-227.

Singh RK and Raghuvanshi SS (1989) Plantlet regeneration from nodal segment and shoot tip derived explants of lentil. Lens Newslett. 6: 33-35.

Sharma KK, Bhatnagar-Mathur $\mathbf{P}$ and Thorpe TA (2005) Genetic transformation technology: Status and problems. In Vitro Cell. Dev. Biol.-Plant 41: 102-112. 
Talib BS, Safarnejad A, Lahooti M and Bagheri A (2003) Effect of genotype, explant and plant regulator in tissue culture of lentil (Lens culinaris M.). The Third National Conference of Biotechnology, Islamic Republic of Iran: 336-339.

Warkentin TD and McHughen A (1993) Regeneration from lentil cotyledonary nodes and potential of this explant for transformation by Agrobacterium tumefaciens. Lens Newslett. 20: 26-28.

Williams DJ and McHughen A (1986) Plant regeneration of the legume Lens culinaris M. (lentil) in vitro. Plant Cell, Tissue Organ Cult. 7: 149-153.

Ye G, Mcneil DL, Conner AJ and Hill GD (2002) Multiple shoot formation in lentil (Lens culinaris M.) seeds. New Zealand J. Crop Hort. Sci. 30: 1-8.

Ye G, Mcneil DL, Conner AJ and Hill GD (2002) Multiple shoot formation in lentil (Lens culinaris M.) seeds. New Zealand J. Crop Hort. Sci. 30: 1-8. 